\title{
Adsorption desulfurization study with ionic liquid compound $\mathrm{ZrO}_{2} / \mathrm{PSMIMHSO}_{4}$
}

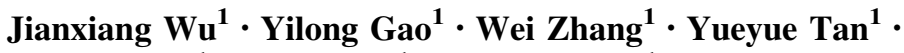 \\ Aomin Tang ${ }^{1} \cdot$ Yong Men ${ }^{1} \cdot$ Bohejin Tang ${ }^{1}$
}

Received: 13 November 2014/ Accepted: 29 January 2016/Published online: 23 February 2016

(c) The Author(s) 2016. This article is published with open access at Springerlink.com

\begin{abstract}
Two ionic liquids 1-methyl-imidazolium-3propylsulfonate (PSMIM) and 1-methyl-imidazolium-3propylsulfonate hydrosulfate ( $\mathrm{PSMIMHSO}_{4}$ ) were synthesized. Their $\mathrm{ZrO}_{2}, \mathrm{ZrOCl}_{2}$ and $\mathrm{ZrO}_{2} / \mathrm{SO}_{4}{ }^{2-}$ derivatives were prepared under different condition and their desulfurization performances were studied. Then compared with traditional materials and their original materials under the same condition, the result showed that $\mathrm{PSMIMHSO}_{4}$ compounded with $\mathrm{ZrO}_{2}$ at mass ratio of $1: 1$ exhibited the superior desulfurization activity at $433 \mathrm{~K}$ for $25 \mathrm{~min}$ with the material/oil $(\mathrm{m} / \mathrm{v})$ of $1: 10$, and its desulfurization rate reached $97.4 \%$.
\end{abstract}

Keywords Ionic liquid · Desulfurization · Adsorption

\section{Introduction}

In recent years, large amounts of fuel oils have been demanded in industries and daily life with the rapid development of society. At the same time, environmental concerns have also attracted more attention [1-3]. That can be attributed to the main exhaust gas $\mathrm{SO}_{x}$, a major source of acid rain, and poison noble metal catalysts that are irreversibly generated by automobiles. Consequently, desulfurization is highly recommended and restricted in oil and automotive industries in the developed countries, and being research focus in both industry and academia. Presently, desulfurization is mainly carried out by

Bohejin Tang

tangbohejin@sues.edu.cn; tangbohejin@sues.edu.com

1 College of Chemistry and Chemical Engineering, Shanghai University of Engineering Science, Shanghai 201620, China catalytic hydrodesulfurization at the industry. This method can effectively remove aliphatic and alicyclic sulfur compounds from gasoline and diesel $[4,5]$, but it is difficult to completely remove thiophene and its derivatives. On the other hand, hydrodesulfurization technology need high cost of equipment and operation as well as other drawbacks [6].

Ionic liquids (ILs) have negligible vapor pressure; therefore, they cannot emit volatile organic compounds (VOCs) to the environment. Due to their salt-like characteristics, they are nonvolatile, are nonflammable, and possess high ionic conductivity. ILs are also a highly solvating and non-coordinating medium. ILs consisting of a cation and anion combination are limitless in number. Their physiochemical properties can be determined by both the cations and anions of the salt. ILs have been recently recognized as environmentally benign alternative solvents due to its advantages in minimizing solvent consumption, guaranteeing catalyst performance, and solving various organic/inorganic compounds, which facilitate the reaction efficiency in homogeneous phase, liquid-liquid separation, and IL solvent-catalyst recycling. In addition, this method can be conducted under moderate reaction conditions and easy to recycle the materials. The method combining the chemical oxidation with ionic liquids extraction was the remarkable advantage of this process over the desulfurization by mere solvent extraction with IL, and it could achieve deep desulfurization [7-11].

In this article, we synthesized 1-methyl-imidazolium-3propylsulfonate (PSMIM) and 1-methyl-imidazolium-3propylsulfonate hydrosulfate $\left(\mathrm{PSMIMHSO}_{4}\right)$ and their derivatives by adding $\mathrm{ZrO}_{2}, \mathrm{ZrOCl}_{2}$ and $\mathrm{ZrO}_{2} / \mathrm{SO}_{4}{ }^{2-}$ as adsorbents, and characterized them. Then we studied the optimum temperature and mass ratio of compound materials, and characterize their desulfurization activity under 
same condition in the desulfurization reaction by gas chromatography.

\section{Experimental}

\section{Preparation of PSMIM and $\mathrm{PSMIMHSO}_{4}$}

1,3-Propanesultone (40.0 g) was completely dissolved in $300 \mathrm{~mL}$ toluene. $\mathrm{N}$-methyl imidazole $(27.0 \mathrm{~g})$ was slowly added with stirring under ice bath. The temperature was slowly raised to $298 \mathrm{~K}$ and maintained for $2 \mathrm{~h}$. The product was then filtered from the mixture liquid and washed with diethyl ether and ether acetate three times, respectively. Then it was obtained after $5 \mathrm{~h}$ of heating at $373 \mathrm{~K}$ [12]. PSMIM (23.3 g) was dissolved in $100 \mathrm{~mL}$ of deionized water. Then sulfuric acid (10.9 g) was slowly added with stirring at room temperature. After that, the temperature was raised to $363 \mathrm{~K}$ and then maintained for $2 \mathrm{~h}$. Deionized water was removed from the product with rotary evaporator [12].

\section{Preparation of $\mathrm{ZrO}_{2}$ and $\mathrm{ZrO}_{2} / \mathrm{SO}_{4}{ }^{2-}$}

Zirconium salt solution was prepared by dissolving $\mathrm{ZrOCl}_{2} \cdot 8 \mathrm{H}_{2} \mathrm{O}(32.2 \mathrm{~g})$ in $800 \mathrm{~mL}$ deionized water, $200 \mathrm{~mL}$ ammonia solution was then added under vigorous stirring to prepare the sediment of $\mathrm{Zr}(\mathrm{OH})_{4}$. After $2 \mathrm{~h}$, the $\mathrm{pH}$ value of the solution was adjusted to 10.3 and stabilized for another $12 \mathrm{~h}$. $\mathrm{Zr}(\mathrm{OH})_{4}$ was filtered from the solution and washed with deionized water to remove $\mathrm{Cl}^{-}[13,14] . \mathrm{ZrO}_{2}$ was grinded into powder with the size smaller than 100 mesh, then added into $100 \mathrm{~mL} 0.1 \mathrm{~mol} / \mathrm{L} \cdot \mathrm{H}_{2} \mathrm{SO}_{4}$ solution. After $24 \mathrm{~h}$, the solid was filtered and dried at $373 \mathrm{~K}$ for $2 \mathrm{~h}$. After drying, the sample was calcined at $893 \mathrm{~K}$ for $6 \mathrm{~h}$ [14].

\section{Preparation of compound systems}

$\mathrm{PSMIMHSO}_{4}$ was mixed with $\mathrm{ZrOCl}_{2} \cdot 8 \mathrm{H}_{2} \mathrm{O}$ named PSC at the mass ratio of $1: 1$ at $433 \mathrm{~K}$ for $2 \mathrm{~h}$, $\mathrm{PSMIMHSO}_{4}$ was mixed with $\mathrm{ZrO}_{2}$ named PSO and $\mathrm{ZrO}_{2} / \mathrm{SO}_{4}{ }^{2-}$ named PSS under same condition.

\section{Characterization and evaluation of the catalyst}

Infrared spectrometer (AVATAR 370 from Thermo Nicolet) was used to analyze at $500-4000 \mathrm{~cm}^{-1}$.

X-ray diffractometer (Deutschland RUKER D2 PHASER) was scanned with $\mathrm{CuK} \alpha$ in the range of $10^{\circ}-80^{\circ}$ at a rate of $0.02 \mathrm{~s}^{-1}$.

PSMIM $^{1} \mathrm{HNMR}\left(400 \mathrm{MHz}, \quad \mathrm{D}_{2} \mathrm{O}\right): \quad \delta 2.138(\mathrm{~m}, \quad 2 \mathrm{H}$, $J=7.2 \mathrm{~Hz}), \quad 2.822(\mathrm{t}, 2 \mathrm{H}, \quad J=7.2 \mathrm{~Hz}), 3.806(\mathrm{~s}, 3 \mathrm{H})$, 4.270(t, 2H, $J=7.2 \mathrm{~Hz}), \quad 7.365(\mathrm{~s}, 1 \mathrm{H}), \quad 7.437(\mathrm{~s}, 1 \mathrm{H})$, 8.655(s, 1H). ${ }^{13} \mathrm{CNMR}\left(400 \mathrm{MHz}, \mathrm{D}_{2} \mathrm{O}\right): \delta 25.11,35.73$, 47.24, 47.72, 122.16, 123.76, 136.17.

$\mathrm{PSMIMHSO}_{4}^{1} \mathrm{HNMR}\left(400 \mathrm{MHz}, \mathrm{D}_{2} \mathrm{O}\right): \quad \delta 2.135(\mathrm{t}, 2 \mathrm{H}$, $J=7.2 \mathrm{~Hz}), 2.745(\mathrm{~s}, 2 \mathrm{H}), 3.717(\mathrm{~s}, 3 \mathrm{H}), 4.181(\mathrm{t}, 2 \mathrm{H}$, $J=7.2 \mathrm{~Hz}), 7.271(\mathrm{~s}, 1 \mathrm{H}), 7.339(\mathrm{~s}, 1 \mathrm{H}), 8.560(\mathrm{~s}, 1 \mathrm{H})$. ${ }^{13} \mathrm{CNMR}\left(400 \mathrm{MHz}, \mathrm{D}_{2} \mathrm{O}\right): \delta 24.99,35.65,47.15,47.65$, 122.10, 123.71, 136.06.

Elemental analyses were performed on a Perkin-Elmer 2400 elemental analyzer for C, H, N and S. Anal. calc. for PSMIM: C, $41.18 \%$; H, $5.88 \%$; N, $13.73 \%$; S, $15.69 \%$; found: $41.24 \% ; \mathrm{H}, 5.83 \%$; N, $13.74 \%, \mathrm{~S}, 15.65 \%$. Anal. calc. for $\mathrm{PSMIMHSO}_{4}$ : C, $27.81 \%$;, $4.64 \%$; N, $9.27 \%$; S, $21.19 \%$; found: C, $27.83 \% ; \mathrm{H}, 4.60 \%$; N, $9.33 \%$; , $21.14 \%$.

Compound ILs was washed with deionized water and removed from the test tube. The un-reacted $\mathrm{PSMIMHSO}_{4}$ was filtered. The solid was dried at $373 \mathrm{~K}$, and then put into the tube furnace at temperature of $393 \mathrm{~K}$ under the protection of $\mathrm{N}_{2}$, to adsorb pyridine vapor for $30 \mathrm{~min}$.

\section{Desulfurization}

Benzothiophene (BT, $5.0 \mathrm{~g}$ ) was completely dissolved into n-heptane to prepare 5000 ppm model oils. Material $(0.5 \mathrm{~g})$ and $5 \mathrm{~mL}$ of $5000 \mathrm{ppm}$ benzothiophene (BT) solution were added into a tube. The tube was located in the water bath kettle at the desired temperature and stirred with the speed of $10,000 \mathrm{r} / \mathrm{min}$. Then subnatant was injected into gas chromatography to check the sulfur residue in the solute. The conditions of gas chromatography: keeping the initial temperature at $403 \mathrm{~K}$ for $2 \mathrm{~min}$, then raising the temperature to $533 \mathrm{~K}$ at the rate of $10 \mathrm{~K} / \mathrm{min}$ and then maintaining $8 \mathrm{~min}$. The injection volume of the sample is $5 \mu \mathrm{L}$.

Desulfurization efficiency is obtained using the internal standard method. The calculation formula is:

$W=\frac{C_{0}-C_{X}}{C_{0}} \times 100 \%$

where $W$ is desulfurization rate, $C_{0}$ is the initial sulfur content of the oil, $C_{x}$ is the sulfur content of the oil after desulfurization.

\section{Result and discussion}

\section{Characterization}

Figure 1 shows the FT-IR spectra of ionic liquids. The peaks at 3156,3116 and $1575 \mathrm{~cm}^{-1}$ represent $-\mathrm{N}-\mathrm{H}-\mathrm{C}-\mathrm{H}$ and $-\mathrm{C}=\mathrm{N}-$ stretching vibration of the imidazole ring, respectively. The $\mathrm{C}-\mathrm{H}$ stretching vibration of $\mathrm{CH}_{2}$ was observed at $2965 \mathrm{~cm}^{-1}$, the bands at 1487 and $1398 \mathrm{~cm}^{-1}$ 


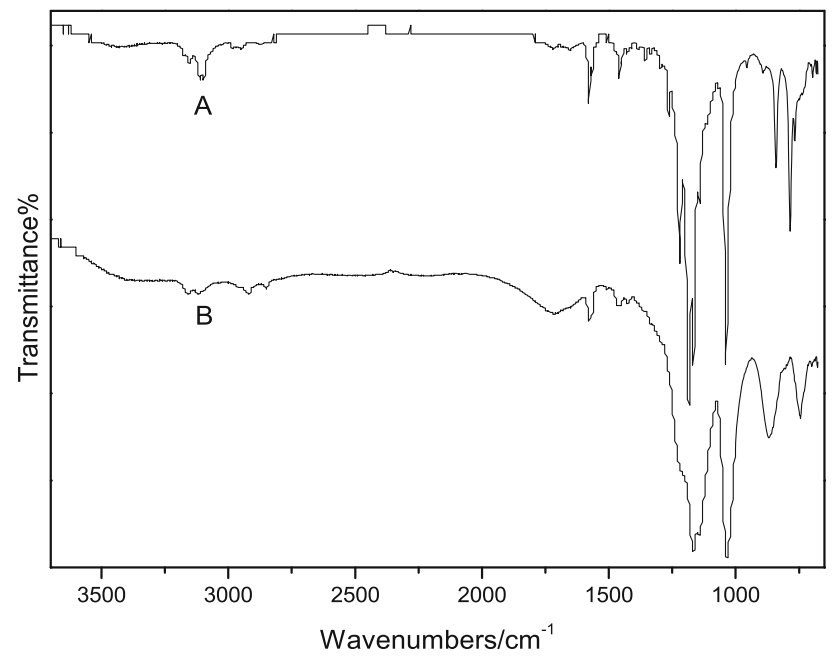

Fig. 1 FT-IR of ionic liquids $A$ : PSMIM and $B$ : $\mathrm{PSMIMHSO}_{4}$

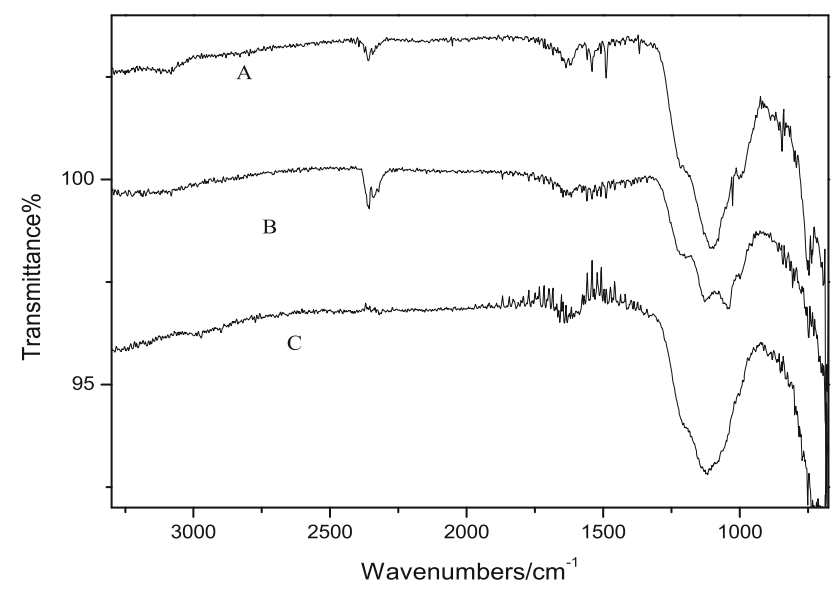

Fig. 2 FT-IR of solid acid prepared under different conditions $A$ : $\mathrm{ZrO}_{2} / \mathrm{SO}_{4}{ }^{2-}$ adsorb pyridine, $B$ : PSO adsorb pyridine and $C: \mathrm{ZrO}_{2} /$ $\mathrm{SO}_{4}{ }^{2-}$

are formation vibration of $\mathrm{N}-\mathrm{CH}_{2}$ and $\mathrm{N}-\mathrm{CH}_{3}$. The peak at $749 \mathrm{~cm}^{-1}$ is the bending vibration of the imidazole ring. Meanwhile, the bands at 1170 and $1130 \mathrm{~cm}^{-1}$ are assigned to the $\mathrm{S}=\mathrm{O}$ asymmetric and symmetric stretching vibrations of the $-\mathrm{SO}_{3} \mathrm{H}$ group for the five kinds of ionic liquids [12].

Figure 2 is FT-IR of solid acid prepared under different conditions. $\mathrm{ZrOCl}_{2} \cdot 8 \mathrm{H}_{2} \mathrm{O}$ is completely dissolved into $\mathrm{PSMIMHSO}_{4}$ at $433 \mathrm{~K}$. So the characteristic peaks of $\mathrm{ZrOCl}_{2} \cdot 8 \mathrm{H}_{2} \mathrm{O}$ do not show up. The peak at $750 \mathrm{~cm}^{-1}$ is the $\mathrm{Zr}-\mathrm{O}-\mathrm{Zr}$ or $\mathrm{O}-\mathrm{Zr}-\mathrm{O}$ vibration of $\mathrm{ZrO}_{2} / \mathrm{SO}_{4}{ }^{2-}$. At the same times, the peak from $1130 \mathrm{~cm}^{-1}$ is $\mathrm{S}=\mathrm{O}$ vibration of $\mathrm{ZrO}_{2} /$ $\mathrm{SO}_{4}{ }^{2-}$. The peaks at 1450 and $1540 \mathrm{~cm}^{-1}$ are characteristic peak of pyridine to check the acid sites. Meanwhile the peaks at 1300 and $1550 \mathrm{~cm}^{-1}$ represent $-\mathrm{C}=\mathrm{C}$ and $\mathrm{C}=\mathrm{N}-$ stretching vibration of pyridine. On the other hand, the peak at $1625 \mathrm{~cm}^{-1}$ is $\mathrm{O}-\mathrm{H}$ formation vibration and $3400 \mathrm{~cm}^{-1}$ is $\mathrm{O}-\mathrm{H}$ stretching vibration $[14,15]$.

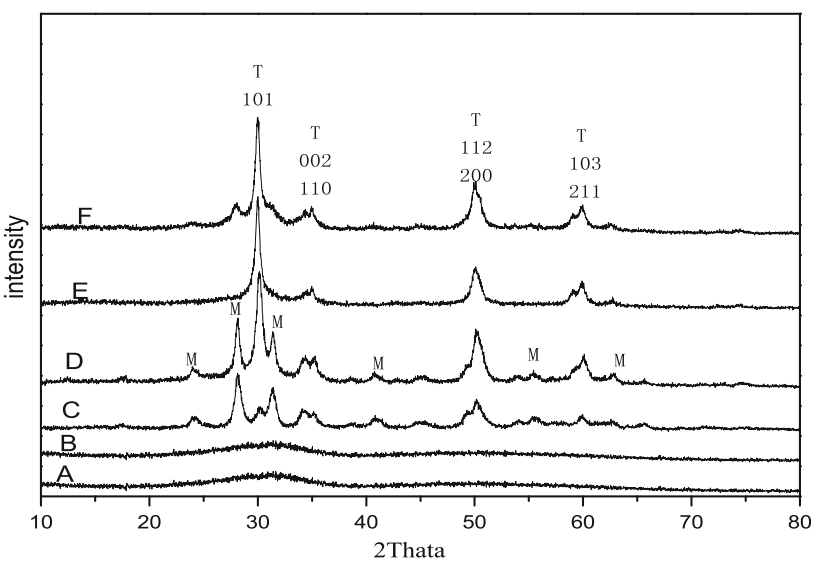

Fig. 3 XRD of under different conditions of preparing solid acid ( $T$ tetragonal, $M$ monoclinic) $A: \mathrm{ZrO}_{2}-433 \mathrm{~K}, B$ : PSO, $C: \mathrm{ZrO}_{2}-$ $893 \mathrm{~K}, D: \mathrm{ZrO}_{2} / \mathrm{SO}_{4}{ }^{2-} 893 \mathrm{~K}, E$ : PSO calcined at $893 \mathrm{~K}$ and $F$ : PSO calcined at $893 \mathrm{~K}$ after desulfurization

XRD patterns of the solid acids under different conditions are shown in Fig. 3. XRD patterns of all solid acids at $30^{\circ}, 35^{\circ}, 50^{\circ}$ and $60^{\circ}$ are the characteristic feature of tetragonal zirconia. In addition, the XRD result shows the presence of a monoclinic zirconia phase along with major tetragonal zirconia. The hump at $28^{\circ}$ in the fuel-lean sample is characteristic of the monoclinic phase. The calcined $\mathrm{ZrO}_{2}$ at $433 \mathrm{~K}$ appears a very broad peak from $\mathrm{A}$ and $\mathrm{B}$. The calcined $\mathrm{ZrO}_{2}$ at $893 \mathrm{~K}$ appears the characteristic peak from $\mathrm{C}$. Compared with $\mathrm{C}$, the amount of tetragonal phase is gradually increasing in the $\mathrm{D}$ and $\mathrm{E}$, especially in the $\mathrm{E}$ which has weak monoclinic peaks [13-17].

\section{The effect of different mass ratio at different temperatures}

The effect of reaction temperature on compound ionic liquids is listed in Table 1 . The results show that the desulfurization rate of compound ionic liquids increases with the increase of the reaction temperature range from 313 to $353 \mathrm{~K}$ and thereafter remained nearly constant, indicating a nearly equilibrium desulfurization rate. The optimum reaction temperature is found to be $353 \mathrm{~K}$.

The effect of PSMIMHSO $4 / \mathrm{ZrO}_{2}$ mass ratios on the desulfurization rate is listed in Table 1 . The mass ratio of $\mathrm{PSMIMHSO}_{4} / \mathrm{ZrO}_{2}$ is $1: 1$, the desulfurization rate increases slightly. The main reason is that the ratio of $\mathrm{HSO}_{4}{ }^{-}$ increased with $\mathrm{PSMIMHSO}_{4}, \mathrm{ZrO}_{2}$ is easy to compound with $\mathrm{HSO}_{4}{ }^{-}$. So the adsorbing activity improves with the desulfurization rate increasing. At the same time, when the mass of $\mathrm{ZrO}_{2}$ decrease, the adsorbing activity also decline. Therefore, the optimum PSMIMHSO ${ }_{4} / \mathrm{ZrO}_{2}$ mass ratio is $1: 1$. 
Table 1 Effect of different mass ratio at different temperatures

\begin{tabular}{lllll}
\hline Temperature $(\mathrm{K})$ & $2: 1(\%)^{\mathrm{a}}$ & $1: 1(\%)^{\mathrm{a}}$ & $1: 2(\%)^{\mathrm{a}}$ & $1: 3^{\mathrm{a}}(\%)$ \\
\hline 313 & 33.9 & 47.1 & 38.9 & 31.3 \\
323 & 60.1 & 70.3 & 65.1 & 56.5 \\
333 & 78.2 & 88.8 & 81.4 & 73.7 \\
343 & 83.9 & 94.6 & 87.1 & 80.6 \\
353 & 86.4 & 97.4 & 90.4 & 83.1 \\
363 & 86.6 & 97.5 & 90.1 & 83.5 \\
373 & 86.2 & 97.2 & 90.2 & 83.3 \\
\hline
\end{tabular}

Condition: the time is $25 \mathrm{~min}$, the amount of PSO is $0.5 \mathrm{~g}$

a The mass ratio of $\mathrm{PSMIMHSO}_{4} / \mathrm{ZrO}_{2}(\mathrm{~m} / \mathrm{m})$

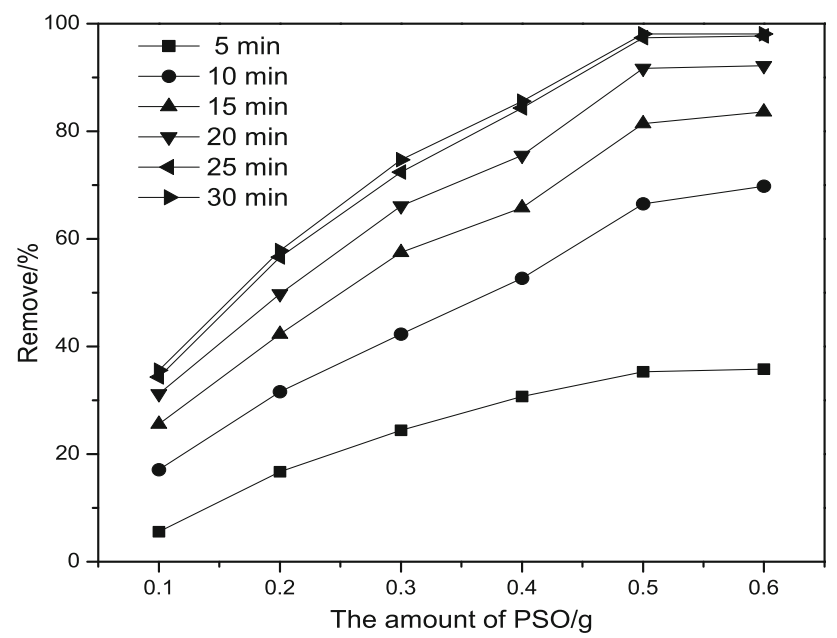

Fig. 4 The effect of the amount of PSO and time condition: the mass ratio of $\mathrm{PSMIMHSO}_{4} / \mathrm{ZrO}_{2}(\mathrm{~m} / \mathrm{m})$ is $1: 1$, the temperature is $353 \mathrm{~K}$

\section{The effect of the amount of PSO and time}

The amount of PSO had a great influence on adsorption of BT. When the amount of PSO increased from 0.1 to $0.5 \mathrm{~g}$, the sulfur removal increased remarkably from 34.3 to $97.4 \%$, but slowly from $97.4 \%$ in $0.5 \mathrm{~g}$ to $98.1 \%$ in $0.6 \mathrm{~g}$. The result indicated that the amount of PSO had a significant effect on removal of BT in the desulfurization reaction. To evaluate the role of the time on the reaction efficiency, the adsorption of BT was performed in adsorption desulfurization of BT system. Sulfur removal increased rapidly at the initial stage, but slowly from $97.4 \%$ in $25 \mathrm{~min}$ to $98.1 \%$ in $30 \mathrm{~min}$. Thus, it was suitable to carry out the desulfurization reaction with $0.5 \mathrm{~g}$ in 25 min (Fig. 4).

\section{The recycled activity of PSO}

The property of the PSO is the reusability. The activities of recycled adsorbent are investigated carefully (Fig. 5). The PSO has high stability, and the recycled adsorbing

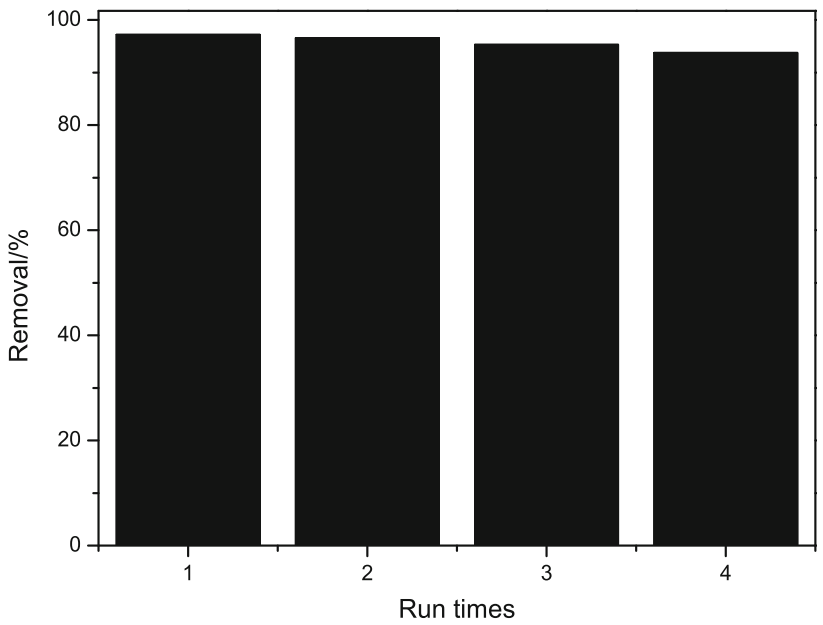

Fig. 5 Recycled activity of PSO

activities are still very high. The rate of desulfurization is still $93.8 \%$ after the PIL has been recycled for 4 times.

\section{Desulfurization rate of different materials}

For the ionic liquid PSMIM and the sulfonic acid group functionalized ionic liquid $\mathrm{PSMIMHSO}_{4}$, the acid sites interact well with benzothiophene. At the same time, benzothiophene could be extracted by ionic liquid.

$\mathrm{ZrO}_{2} / \mathrm{SO}_{4}{ }^{2-}, \mathrm{ZrO}_{2}$ and $\mathrm{ZrOCl}_{2} \cdot 8 \mathrm{H}_{2} \mathrm{O}$ all have higher desulfurization ability from Table $2 . \mathrm{ZrO}_{2}$ is not only BrÖnsted acid, but also Lewis acid, which could coordinate with $\mathrm{S}$ element of benzothiophene [18]. The surface of $\mathrm{ZrO}_{2} / \mathrm{SO}_{4}{ }^{2-}$ also has both the acidity of BrÖnsted acid [19] and Lewis acid [20], so $\mathrm{ZrO}_{2} / \mathrm{SO}_{4}{ }^{2-}$ could adsorb benzothiophene. But, due to the influence of Lewis acid site adsorbing water, the rates of desulfurization of $\mathrm{ZrO}_{2} / \mathrm{SO}_{4}{ }^{2-}, \mathrm{ZrO}_{2}$ and $\mathrm{ZrOCl}_{2} \cdot 8 \mathrm{H}_{2} \mathrm{O}$ are weaker than PSO.

The desulfurization rate of PSS is significantly improved in comparison with $\mathrm{SO}_{4}{ }^{2-} / \mathrm{ZrO}_{2}$, due to the temperature 
Table 2 Desulfurization rate of different materials at $353 \mathrm{~K}$ for $25 \mathrm{~min}$

\begin{tabular}{lll}
\hline The sample number & Component & $\begin{array}{l}\text { Desulfurization } \\
\text { rate }(\%)\end{array}$ \\
\hline 1 & PSMIM & 86.3 \\
2 & $\mathrm{PSMIMHSO}_{4}$ & 90.6 \\
3 & $\mathrm{ZrO}_{2}$ & 90.2 \\
4 & $\mathrm{ZrO}_{2} / \mathrm{SO}_{4}{ }^{2-}$ & 87.3 \\
5 & $\mathrm{ZrOCl}_{2} \cdot 8 \mathrm{H}_{2} \mathrm{O}$ & 92.2 \\
6 & $\mathrm{PSO}$ & 97.4 \\
7 & $\mathrm{PSS}$ & 93.5 \\
8 & $\mathrm{PSC}$ & 90.1 \\
\hline
\end{tabular}

increasing which increase the amount of $\mathrm{SO}_{4}{ }^{2-}$ in the surface of solid acid [18]. Solid acidity is strong to carbonize ionic liquid partially, and block acid sites on the surface of solid acid to reduce the material activity, so its desulfurization rate is lower than PSO. For $\mathrm{Zr}$ element, it can be determined that binding structure of $\mathrm{SO}_{4}{ }^{2-}$ to $\mathrm{Zr}$ ions exhibits the bridged bidentate form [21]. As the $\mathrm{SO}_{4}{ }^{2-}$ group existed, due to the strong attracting electrons from $\mathrm{Zr}$ ions via two covalent $\mathrm{S}=\mathrm{O}$ bonds, the center of metal atom lacks electrons severely, thus strong Lewis acidic strength is generated (Fig. 2), which could adsorb benzothiophene easily. That's the reason why the desulfurization rate of PSO is higher than PSS.

\section{Conclusions}

In the present investigation, PSMIM and $\mathrm{PSMIMHSO}_{4}$ were successfully prepared. Then two ionic liquids mixed with $\mathrm{ZrO}_{2}$ at room temperature and compounded with $\mathrm{ZrO}_{2}$ at $433 \mathrm{~K}$ which displayed solid acidity. The best reaction temperature was determined at $353 \mathrm{~K}$ with using $\mathrm{PSMIMHSO}_{4}$ compounded with $\mathrm{ZrO}_{2}$ at $433 \mathrm{~K}$, whose the optimum mass ratio is $1: 1$. Through the comparison for the materials' activity of PSMIM, PSMIMHSO ${ }_{4}, \mathrm{ZrO}_{2}, \mathrm{ZrO}_{2} /$ $\mathrm{SO}_{4}{ }^{2-}, \mathrm{ZrOCl}_{2}, \mathrm{PSO}$, PSS and PSC, the desulfurization activity of PSO was higher than others under the same conditions. The desulfurization efficiency of PSO reached $97.4 \%$.

Acknowledgments Research was sponsored by The Program for Professor of Special Appointment (Eastern Scholar) at Shanghai Institutions of Higher Learning and the Scientific Research Foundation for the Returned Overseas Chinese Scholars, State Education Ministry.

Open Access This article is distributed under the terms of the Creative Commons Attribution 4.0 International License (http:// creativecommons.org/licenses/by/4.0/), which permits unrestricted use, distribution, and reproduction in any medium, provided you give appropriate credit to the original author(s) and the source, provide a link to the Creative Commons license, and indicate if changes were made.

\section{References}

1. Breysse M, Djega-Mariadassou G, Pessayre S, Geantet C, Vrinat M, Pérot G, Lemaire M (2003) Deep desulfurization: reactions, catalysts and technological challenges. Catal Today 84:129-138

2. Ma X, Zhou A, Song C (2007) A novel method for oxidative desulfurization of liquid hydrocarbon fuels based on catalytic oxidation using molecular oxygen coupled with selective adsorption. Catal Today 123:276-284

3. Yu M, Li Z, Ji Q, Wang S, Su D, Lin Y (2009) Effect of thermal oxidation of activated carbon surface on its adsorption towards dibenzothiophene. Chem Eng J 148:242-247

4. Liu H, Tao GH, Evans DG, Kou Y (2005) Solubility of $\mathrm{C}_{60}$ in ionic liquids. Carbon 43:1782-1785

5. Chum HL, Koch V, Miller L, Osteryoung R (1975) Electrochemical scrutiny of organometallic iron complexes and hexamethylbenzene in a room temperature molten salt. J Am Chem Soc 97:3264-3265

6. Robinson J, Bugle R, Chum H, Koran D, Osteryoung R (1979) Osteryoung, Proton and carbon-13 nuclear magnetic resonance spectroscopy studies of aluminum halide-alkylpyridinium halide molten salts and their benzene solutions. J Am Chem Soc 101:3776-3779

7. Vidal L, Riekkola ML, Canals A (2012) Canals, ionic liquidmodified materials for solid-phase extraction and separation: a review. Anal Chim Acta 715:19-41

8. Wu B, Kuang Y, Zhang Y, Zhang X, Chen J (2012) Carbonization of ionic liquid polymer-functionalized carbon nanotubes for high dispersion of PtRu nanoparticles and their electrocatalytic oxidation of methanol. J Mater Chem 22:13085-13090

9. Revelli AL, Mutelet F, Jaubert JN (2010) Extraction of benzene or thiophene from $\mathrm{n}$-heptane using ionic liquids. NMR and thermodynamic study. J Phys Chem B 114:4600-4608

10. Su BM, Zhang S, Zhang ZC (2004) Structural elucidation of thiophene interaction with ionic liquids by multinuclear NMR spectroscopy. J Phys Chem B 108:19510-19517

11. Gutel T, Santini CC, Pádua AA, Fenet B, Chauvin Y, Canongia Lopes JN, Bayard F, Costa Gomes MF, Pensado AS (2008) Interaction between the $\pi$-system of toluene and the imidazolium ring of ionic liquids: a combined NMR and molecular simulation study. J Phys Chem B 113:170-177

12. Wu Q, Chen H, Han M, Wang D, Wang J (2007) Transesterification of cottonseed oil catalyzed by Brønsted acidic ionic liquids. Ind Eng Chem Res 46:7955-7960

13. Kumar S, Srivastava VC, Badoni R (2011) Studies on adsorptive desulfurization by zirconia based adsorbents. Fuel 90:3209-3216

14. Li X, Nagaoka K, Olindo R, Lercher JA (2006) Synthesis of highly active sulfated zirconia by sulfation with $\mathrm{SO}_{3}$. J Catal 238:39-45

15. Dong W-S, Lin F-Q, Liu C-L, Li M-Y (2009) Synthesis of $\mathrm{ZrO}_{2}$ nanowires by ionic-liquid route. $\mathrm{J}$ Colloid Interface Sci 333:734-740

16. Yadav GD, Ajgaonkar NP, Varma A (2012) Preparation of highly superacidic sulfated zirconia via combustion synthesis and its application in Pechmann condensation of resorcinol with ethyl acetoacetate. J Catal 292:99-110 
17. Reddy BM, Patil MK, Rao KN, Reddy GK (2006) An easy-to-use heterogeneous promoted zirconia catalyst for Knoevenagel condensation in liquid phase under solvent-free conditions. J Mol Catal A 258:302-307

18. Guo HF, Yan P, Hao XY, Wang ZZ (2008) Influences of introducing $\mathrm{Al}$ on the solid super acid $\mathrm{SO}_{4}{ }^{2-} / \mathrm{SnO}_{2}$. Mater Chem Phys 112:1065-1068

19. Wang B, Zhu J, Ma H (2009) Desulfurization from thiophene by $\mathrm{SO}_{4}{ }^{2-} / \mathrm{ZrO}_{2}$ catalytic oxidation at room temperature and atmospheric pressure. J Hazard Mater 164:256-264
20. Sohn JR, Seo DH (2003) Preparation of new solid superacid catalyst, zirconium sulfate supported on $\gamma$-alumina and activity for acid catalysis. Catal Today 87:219-226

21. Bolis V, Magnacca G, Cerrato G, Morterra C (1997) Morterra, Microcalorimetric characterization of structural and chemical heterogeneity of superacid $\mathrm{SO}_{4} / \mathrm{ZrO}_{2}$ systems. Langmuir $13: 888-894$ 